\title{
Magnetic and electronic properties of $M-\mathrm{Ba}-\mathrm{Cu}-\mathrm{O}(M=\mathrm{Y}, \mathrm{Er}$, $\mathrm{Eu})$
}

\author{
H. Jenny, B. Walz, G. Leeman, V. Geiser, S. Jost, T. Frey, and H.-J. Güntherodt \\ Institut für Physik, Universität Basel, Klingelbergstr. 82, CH-4056 Basel, Switzerland
}

(Received 1 July 1987; accepted 24 August 1987)

Various high- $T_{c}$ superconductors of the $\mathrm{La}-(\mathrm{Ba}, \mathrm{Sr})-\mathrm{Cu}-\mathrm{O}$ and the $M-\mathrm{Ba}-\mathrm{Cu}-\mathrm{O}$ systems with $M=\mathrm{Y}, \mathrm{Er}$, and Eu have been prepared by the solid-state reaction method. Single-phase samples with no additional diffraction peaks as verified by $\mathrm{X}$-ray diffraction (XRD) measurements have been obtained. Measurements of the electrical resistivity and of the magnetization showed sharp superconducting transitions with a width of $1 \mathrm{~K}$. The measurements of the magnetic susceptibility have been extended above room temperature up to $770 \mathrm{~K}$. There is clear evidence for the formation of a magnetic moment in all $M-\mathrm{Ba}-\mathrm{Cu}-\mathrm{O}$ samples. Monochromated x-ray photoelectron spectroscopy (MXPS) valence band and x-ray photoelectron spectroscopy (XPS) core level spectra have been measured on various samples at room temperature and at liquid nitrogen temperature.

\section{INTRODUCTION}

Since the first publication by Bednorz and Müller ${ }^{1}$ on the new high- $T_{c}$ superconductors based on RE, Y$\mathrm{Ba}(\mathrm{Sr})-\mathrm{Cu}$-oxides, ${ }^{2,3}$ this field has developed very rapidly by exploring new characteristics like high critical current densities. ${ }^{4}$ However, there is a need to understand the physics of these oxides; therefore it is our aim to study a variety of physical properties on these materials. We extend the field by applying our techniques to the new superconductors since we have longstanding experience in using various experimental analyses, such as scanning tunneling microscopy (STM) and rapid quenching. In the present work we report, as a first step, on the preparation of the oxides, the characterization by $\mathrm{XRD}$, the electrical resistivity measurements, the magnetic properties, and the use of photoelectron spectroscopy. The studies by STM and rapid quenching have begun to show interesting results but are still under way.

\section{EXPERIMENTS AND RESULTS}

The $M \mathrm{Ba}_{2} \mathrm{Cu}_{3} \mathrm{O}_{7-x}$ samples were prepared by the solid-state reaction method with appropriate mixtures of starting powders of $\mathrm{M}_{2} \mathrm{O}_{3}, \mathrm{BaCO}_{3}$, and $\mathrm{CuO}$. The mixtures were treated in a fashion similar to that already described in the literature. ${ }^{2,3,5}$ Table I gives a detailed listing of the sintering temperatures (with an accuracy of $+(-10 \mathrm{~K}$ ) and the annealing times used to obtain the superconducting samples. In contrast to the $\mathrm{La}-(\mathrm{Ba}, \mathrm{Sr})-\mathrm{Cu}$ oxides, the $\mathrm{M}-\mathrm{Ba}-\mathrm{Cu}$ oxides were fired only in oxygen flow. No decomposition was observed up to the maximum annealing temperatures indicated. It turned out that the $M-\mathrm{Ba}-\mathrm{Cu}-\mathrm{O}$ samples had to be cooled down slowly in oxygen flow to prevent them from losing their superconducting properties.
The electrical resistivity of the samples has been measured by a standard ac four-probe technique using a frequency of $983 \mathrm{~Hz}$. The amplitude of the current through the samples was in the milliampere range. The temperature was measured with a $\mathrm{Pt}$ resistor above $77 \mathrm{~K}$ and with a Ge resistor below $77 \mathrm{~K}$. Several of the measured resistivity versus temperature plots are summarized in Fig. 1.

In $\mathrm{La}-\mathrm{Sr}-\mathrm{Cu}-\mathrm{O}$ compounds the onset of superconductivity is found at $36 \mathrm{~K}$, and zero resistance is reached at $33.5 \mathrm{~K}$. The single-phase $M \mathrm{Ba}_{2} \mathrm{Cu}_{3} \mathrm{O}_{7-x}$ samples showed onsets and midpoints of the superconducting transition above $90 \mathrm{~K}$, with the exception of $\mathrm{YBa}_{2} \mathrm{Cu}_{3} \mathrm{O}_{7-x}$, for which the midpoint was found around $81 \mathrm{~K}$. The multiphase $\mathrm{Y}_{1.2} \mathrm{Ba}_{0.8} \mathrm{Cu}_{3} \mathrm{O}_{x}$ sample becomes superconducting at a temperature that lies $5 \mathrm{~K}$ higher than in single-phase $\mathrm{YBa}_{2} \mathrm{Cu}_{3} \mathrm{O}_{7-x}$. The width of transition of our samples is quite small, about $1 \mathrm{~K}$. Only the $\mathrm{Er}-\mathrm{Ba}-\mathrm{Cu}-\mathrm{O}$ sample showed a width of several degrees. This is caused by a tail in the lower part of the

TABLE I. Sintering conditions for various oxide superconductors.

\begin{tabular}{lcccc}
\hline \hline Sample & $\begin{array}{c}T \\
{\left[{ }^{\circ} \mathrm{C}\right]}\end{array}$ & $\begin{array}{c}\text { Time } \\
{[\mathrm{h}]}\end{array}$ & $\begin{array}{c}\text { Oxygen } \\
\text { treatment }\end{array}$ & $\begin{array}{l}T_{c}^{\text {onset }} \\
{[\mathrm{K}]}\end{array}$ \\
\hline $\mathrm{La}_{1.85} \mathrm{Ba}_{0.12} \mathrm{CuO}_{x}$ & 990 & 36 & $\cdots$ & 33 \\
$\mathrm{La}_{1.8} \mathrm{Sr}_{0.14} \mathrm{CuO}_{x}$ & 990 & 116 & $\cdots$ & 35 \\
$\mathrm{Y}_{1.2} \mathrm{Ba}_{0.8} \mathrm{CuO}_{x}$ & 900 & +5.5 & $x$ & 36 \\
$\mathrm{YBa}_{2} \mathrm{Cu}_{3} \mathrm{O}_{7-x}$ & 990 & 24 & $\cdots$ & 86.9 \\
$\mathrm{ErBa}_{2} \mathrm{Cu}_{3} \mathrm{O}_{7-x}$ & 950 & 69 & $x$ & 81.6 \\
$\mathrm{EuBa}_{2} \mathrm{Cu}_{3} \mathrm{O}_{7-x}$ & 990 & 24 & $x$ & 91.7 \\
$\mathrm{Y}_{0.1} \mathrm{Eu}_{0.9} \mathrm{Ba}_{2} \mathrm{Cu}_{3} \mathrm{O}_{7-x}$ & 990 & 46 & $x$ & 84.2 \\
\hline \hline
\end{tabular}




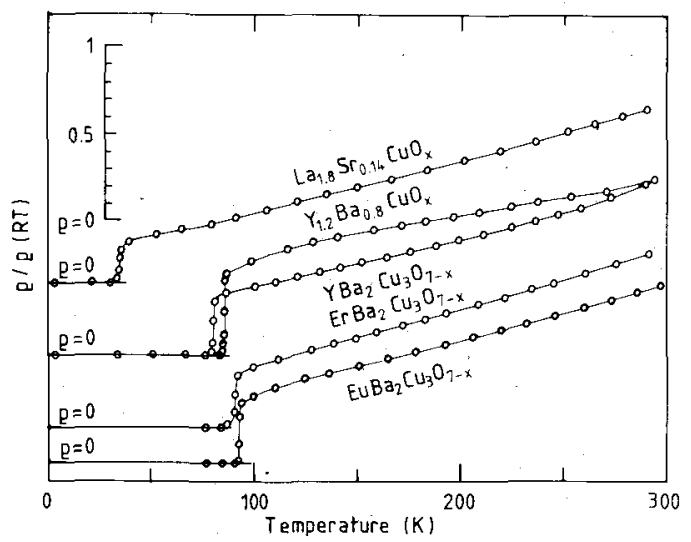

FIG. 1. Typical resistivity curves for various oxide superconductors.

transition. The absolute resistance of our single-phase $M \mathrm{Ba}_{2} \mathrm{Cu}_{3} \mathrm{O}_{7-x}$-type superconductors is of the order of $10^{4} \mu \Omega \mathrm{cm}$ at room temperature. The resistance of $\mathrm{Y}_{1.2} \mathrm{Ba}_{0.8} \mathrm{CuO}_{x}$ is approximately 1000 times larger.

The structures and phases of our samples were investigated by $\mathrm{x}$-ray diffraction in the standard reflection geometry using monochromated $\mathrm{Cu} K_{\alpha}$ radiation. The spectra showed that our $M \mathrm{Ba}_{2} \mathrm{Cu}_{3} \mathrm{O}_{7-x}$ samples were single phased. The structure of $\mathrm{YBa}_{2} \mathrm{Cu}_{3} \mathrm{O}_{7-x}$ is of the same type as that found by Capponi et al. ${ }^{6}$ and is not affected by the substitution of $Y$ by Er or Eu. We noticed a preferred orientation of the (001) planes parallel to the sample surface in $\mathrm{ErBa}_{2} \mathrm{Cu}_{3} \mathrm{O}_{7-x}$.

The magnetic properties of our superconducting samples were investigated below room temperature with a vibrating sample magnetometer. A sharp drop from the paramagnetic into the diamagnetic state was observed at the normal to superconducting state transition. The measurements show that the diamagnetism is lowered as the magnetic field is increased. For $\mathrm{ErBa}_{2} \mathrm{Cu}_{3} \mathrm{O}_{7-x}$ the drop in magnetization was not strong enough even to reach diamagnetism as soon as the field exceeded $0.2 \mathrm{~T}$. This is due to the strong paramagnetism occurring in this material. The difference in magnetization between the onset temperature of superconductivity and $77 \mathrm{~K}$ is plotted versus magnetic field in Fig. 2. The oxides containing $\mathrm{Er}$ and $\mathrm{Eu}$ show a linear decrease of the superconductivity signal with increasing magnetic field, whereas for the $Y$ sample two different slopes are observed, shifting the upper critical field to higher values.

The magnetic behavior of the $\mathrm{La}-(\mathrm{Ba}, \mathrm{Sr})-\mathrm{Cu}-\mathrm{O}$ and $M-\mathrm{Ba}-\mathrm{Cu}-\mathrm{O}$ samples was also investigated above room temperature up to $770 \mathrm{~K}$ using a very sensitive Faraday balance working in air. The results are shown in Fig. 3. The oxygen content was taken to be about 7 for $M \mathrm{Ba}_{2} \mathrm{Cu}_{3}$ oxides $^{7}$ and 4 for $\mathrm{La}-(\mathrm{Ba}, \mathrm{Sr})-\mathrm{Cu}$ oxides. $^{2}$ For $\mathrm{La}_{1.85} \mathrm{Ba}_{0.12} \mathrm{CuO}_{x}$ we found that the susceptibility

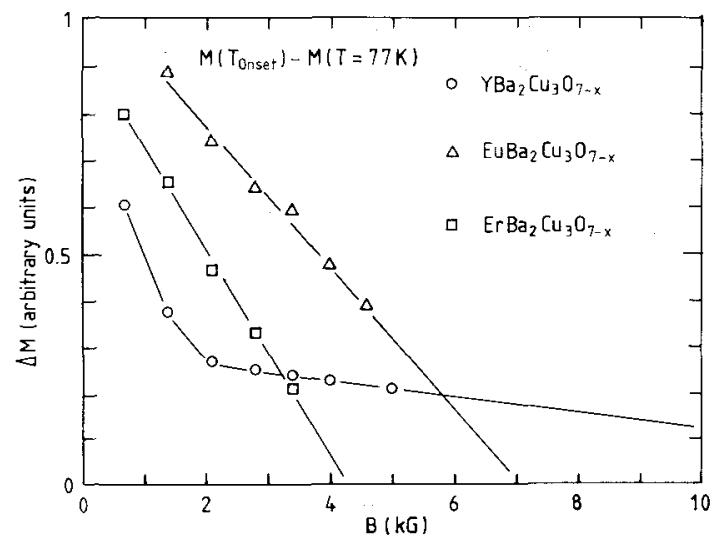

FIG. 2. Difference in the magnetization between onset temperature and $77 \mathrm{~K}$ as a function of the applied magnetic field.

first increased with increasing temperature, then showed a maximum at about $500 \mathrm{~K}$ and became smaller upon further heating. The decrease above $500 \mathrm{~K}$ is due to changes occurring in the sample and is not reproduced upon cooling. The susceptibility of $\mathrm{La}_{1.8} \mathrm{Sr}_{0.14} \mathrm{CuO}_{x}$ is almost temperature independent with the exception of a small maximum at $500 \mathrm{~K}$. For the $M-\mathrm{Ba}-\mathrm{Cu}-\mathrm{O}$ samples a Curie-Weiss-like behavior was observed for all the investigated compositions demonstrating the existence of magnetic moments in these materials. The susceptibilities of $\mathrm{YBa}_{2} \mathrm{Cu}_{3} \mathrm{O}_{7-x}$ and

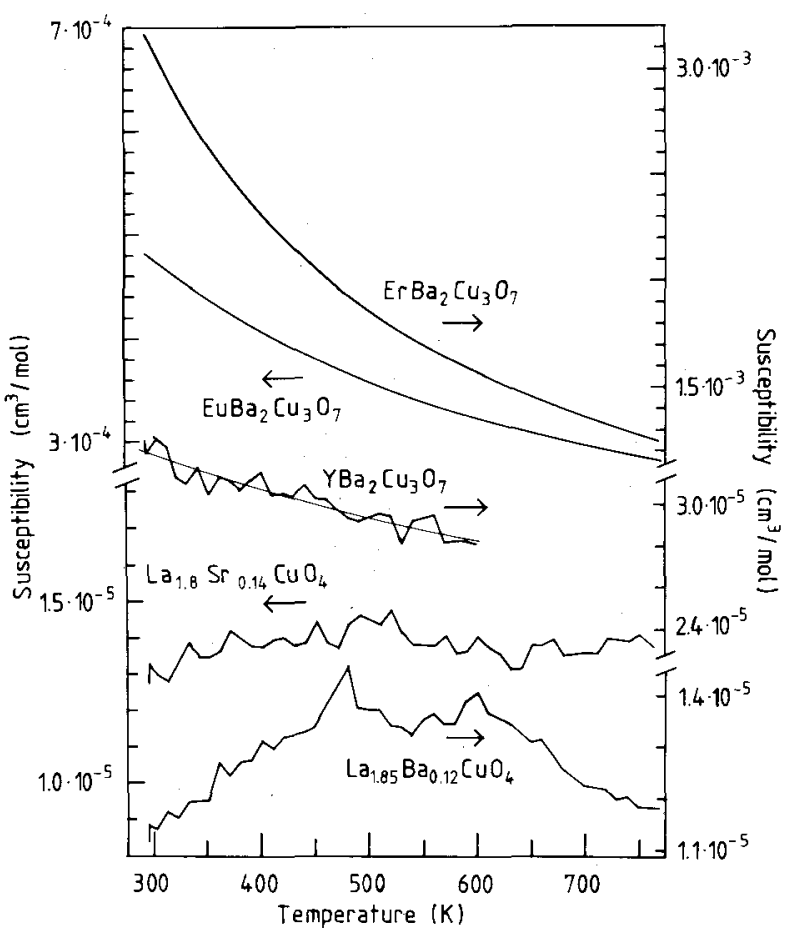

FIG. 3. Magnetic susceptibility above room temperature for various oxide superconductors. 
$\mathrm{ErBa}_{2} \mathrm{Cu}_{3} \mathrm{O}_{7-x}$ were not affected by the heating. Also, $T_{c}$ remained above $77 \mathrm{~K}$ for these two materials, indicating only small changes in the oxygen content of the samples. However, in $\mathrm{EuBa}_{2} \mathrm{Cu}_{3} \mathrm{O}_{7-x}$ superconductivity above liquid nitrogen temperature was lost during heating, and the susceptibility became slightly smaller. At room temperature the susceptibility curve of $\mathrm{YBa}_{2} \mathrm{Cu}_{3} \mathrm{O}_{7-x}$ joins the low-temperature values given by A. Junod et al., ${ }^{8}$ whereas it is smaller by more than a factor of 2 compared to data published by Cava et al. ${ }^{7}$ This discrepancy is not yet understood. The susceptibility of $\mathrm{EuBa}_{2} \mathrm{Cu}_{3} \mathrm{O}_{7-x}$ is in good agreement with a curve published by Murphy et $a l^{9}$; here the small difference can be explained by slightly differing preparation conditions.

Single-phase samples of $\mathrm{La}_{1.85} \mathrm{Ba}_{0.12} \mathrm{CuO}_{x}$, $\mathrm{YBa}_{2} \mathrm{Cu}_{3} \mathrm{O}_{7-x}$, and $\mathrm{EuBa}_{2} \mathrm{Cu}_{3} \mathrm{O}_{7-x}$ have also been investigated by $\mathrm{x}$-ray photoelectron spectroscopy (XPS) and monochromated XPS (MXPS). Samples were carefully cleaned either by scraping in situ with a file or by scraping in $\mathrm{N}_{2}$ flow and transfering them into the vacuum chamber immediately afterward. After cleaning, small shoulders occurring at the $O$ 1s levels had disappeared, but small amounts of carbon could still be detected, probably due to absorption of $\mathrm{CO}$ and $\mathrm{CO}_{2}$ gases at inner surfaces of these not completely dense samples. ${ }^{10}$ Figure 4 shows valence band spectra of La$\mathrm{Ba}-\mathrm{Cu}-\mathrm{O}$ and $\mathrm{Y}-\mathrm{Ba}-\mathrm{Cu}-\mathrm{O}$ taken at room temperature with monochromated $\mathrm{Al} K_{\alpha}$ radiation. The spectra reveal broad features at binding energies of about $4 \mathrm{eV}$. Comparison with published data on the valence band structure of $\mathrm{CuO}^{11}$ and recent calculations of the electronic bandstructure for $\mathrm{La}-\mathrm{Cu}-\mathrm{O}^{12}$ show that this structure originates mainly from $\mathrm{Cu} 3 d$ and $\mathrm{O} 2 p$ electrons. These states almost determine the structure of the valence band. From our spectra we see that the density of states at the Fermi level $\left(E_{f}\right)$ is quite small for both samples.

In Fig. $5 \mathrm{Cu} 2 p_{3 / 2}$ core levels for $\mathrm{YBa}_{2} \mathrm{Cu}_{3} \mathrm{O}_{7-x}$ are shown. They are identical to those obtained for $\mathrm{Eu}-\mathrm{Ba}-$

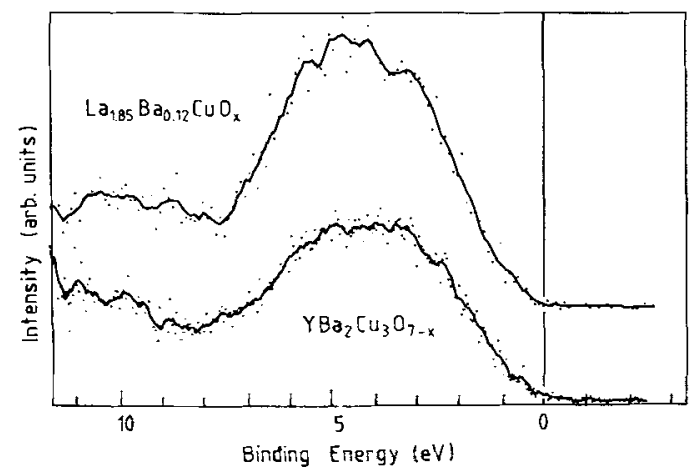

FIG. 4. The MXPS AI $K_{\alpha}$ valence bands of two different oxide superconductors at room temperature.

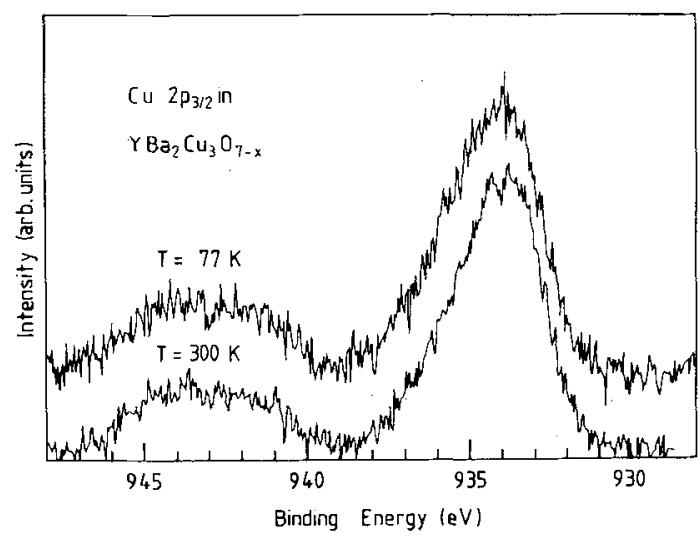

FIG. 5. The $\mathrm{Cu} 2 p_{3 / 2}$ core levels of $\mathrm{YBa}_{2} \mathrm{Cu}_{3} \mathrm{O}_{7-x}$ measured at room temperature and at $77 \mathrm{~K}$ using $\mathrm{Mg} K_{\alpha}$ radiation.

$\mathrm{Cu}-\mathrm{O}$ and $\mathrm{La}-\mathrm{Ba}-\mathrm{Cu}-\mathrm{O}$. We observe that the core level shift with respect to metallic copper and the half width are nearly the same as in $\mathrm{CuO}$.

The $\mathrm{Cu} 2 p$ core levels show a pronounced satellite structure on the higher binding energy side. Such satellites are typical for paramagnetic copper ions. ${ }^{13}$ Here we find a small difference between superconducting oxides and $\mathrm{CuO}$. The intensity of the satellite is slightly decreased in the superconductors, compared to $\mathrm{CuO}$. Electron spectroscopy measurements taken at $77 \mathrm{~K}$ did not reveal dramatic changes in the spectra at all. Only a very small broadening of the $\mathrm{Cu} 2 p$ core levels in $\mathrm{Eu}-$ $\mathrm{Ba}-\mathrm{Cu}-\mathrm{O}$ and $\mathrm{Y}-\mathrm{Ba}-\mathrm{Cu}-\mathrm{O}$ was observed. Within the limit of our resolution of a few percent, we could not see indications for the existence of $\mathrm{Cu}^{3+}$ ions in the samples we investigated. This lack of $\mathrm{Cu}^{3+}$ ions has also been observed by Steiner et al. $^{10}$

Figure 6 shows the $\mathrm{Ba} 3 d_{5 / 2}$ core level at room temperature and at $77 \mathrm{~K}$. We found that this level exhibits a shoulder at the lower binding energy side. The main peak is ascribed to $\mathrm{BaO}$. The smaller peak, which gives

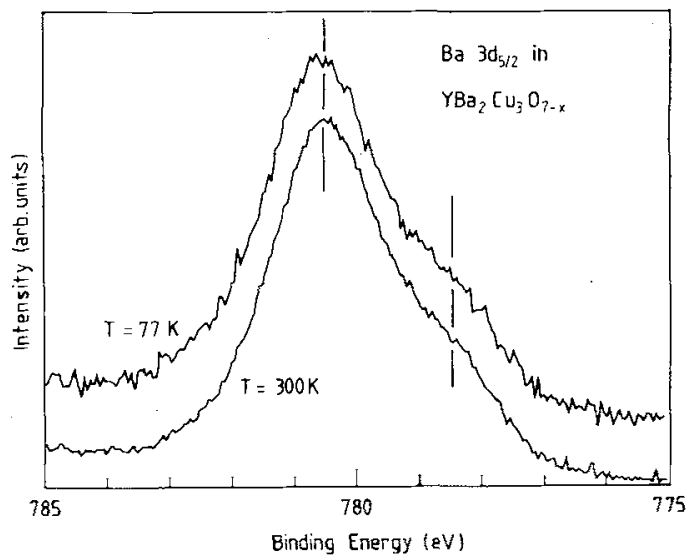

FIG. 6. The $\mathrm{Ba} 3 d_{5 / 2}$ core levels of $\mathrm{YBa}_{2} \mathrm{Cu}_{3} \mathrm{O}_{7-x}$ measured at room temperature and at $77 \mathrm{~K}$ using $\mathrm{Mg} K_{\alpha}$ radiation. 
rise to the shoulder, is shifted in the direction of metallic $\mathrm{Ba}$. From the determination of the structure of $\mathrm{M}-\mathrm{Ba}-$ $\mathrm{Cu}-\mathrm{O}$ we know that there are two $\mathrm{Ba}$ atoms per unit cell in $\mathrm{Y}-\mathrm{Ba}-\mathrm{Cu}-\mathrm{O}$ and $\mathrm{Eu}-\mathrm{Ba}-\mathrm{Cu}-\mathrm{O}$. But as they are positioned at two equivalent sites, the shoulder of the $3 d_{5 / 2}$ peak can not be explained by effects of different chemical environment. The shoulder can, however, be due to the oxygen vacancies near the Ba ions.

The spectra we have obtained for the $\mathrm{Y}, \mathrm{Eu}$, and $\mathrm{La}$ core levels do not differ from those expected for simple oxides. The oxygen $1 s$ level is found to be split into two peaks. This splitting can be attributed to the inequivalent oxygen lattice sites existing in the unit cell.

\section{CONCLUSIONS}

In conclusion we can summarize the following observations for our high- $T_{c}$ oxides: The width of the normal to superconducting state transition is as small as 1 $\mathrm{K}$. The density of states at $E_{f}$ is very small at room temperature. Although the core level spectra are not totally equivalent between the high- $T_{c}$ oxides and $\mathrm{CuO}$ the spectra resemble those of $\mathrm{CuO}$ very much. We do not see $\mathrm{Cu}^{3+}$ ions. The occurring magnetic moments for the $M \mathrm{Ba}_{2} \mathrm{Cu}_{3} \mathrm{O}_{7-x}$ samples make clear that for those materials magnetic moments in the normal state do not exclude the existence of superconductivity.

\section{ACKNOWLEDGMENTS}

We would like to thank P. Oelhafen and D. Ugolini for assistence in performing the electron spectroscopy measurements and $\mathbf{H}$. Thomas for helpful discussions.

Financial support by the Swiss National Science Foundation is gratefully acknowledged.

\section{REFERENCES}

'J. G. Bednorz and K. A. Müller, Z. Phys. B 64, 189 (1986).

${ }^{2}$ R. J. Cava, R. B. van Dover, B. Batlogg, and E. A. Rietman, Phys. Rev. Lett. 58, 408 (1987).

${ }^{3}$ M. K. Wu, J. R. Ashburn, and C. J. Torng, Phys. Rev. Lett. 58, 908 (1987).

${ }^{4}$ P. Chaudhari, R. H. Koch, R. B. Laibowitz, T. R. McGuire, and R J. Gambino, Phys. Rev. Lett. 58, 2684 (1987).

${ }^{5}$ C. W. Chu, P. H. Hor, R. L. Meng, L. Gao, Z. J. Huang, and Y. Q. Wang, Phys. Rev. Lett. 58, 405 (1987).

${ }^{6}$ J. J. Capponi, C. Chaillout, A. W. Hewat, P. Lejay, M. Marezio, N. Nguyen, B. Raveau, J. L. Soubeyroux, J. L. Tholence, and R. Tournier, Europhys. Lett. 3, 1301 (1987).

${ }^{7}$ R. J. Cava, B. Batlogg, R. B. van Dover, D. W. Murphy, S. Sunshine, T. Siegrist, J. P. Remeika, E. A. Rietman, S. Zahurak, and G. P. Espinosa, Phys. Rev. Lett. 58, 1676 (1987).

${ }^{8}$ A. Junod, A. Bezinge, T. Graf, J. L. Jorda, J. Muller, L. Antognazza, D. Cattani, J . Cors, M. Decroux, O. Fischer, M, Banovski, P. Genoud, L. Hoffman, A. A. Manuel, M. Peter, E. Walker, M. François, and K. Yvon, Europhys. Lett. 4, 247 (1987).

${ }^{9}$ D. W. Murphy, S. Sunshine, R. B. van Dover, R. J. Cava, B. Batlogg, S. M. Zahurak, and L. F. Schneemeyer, Phys. Rev. Lett. 58, 1888 (1987).

${ }^{10} \mathrm{P}$. Steiner, V. Kinsinger, I. Sander, B. Siegwart, S. Hüfner, and C. Politis, Z. Phys. B 67, 19 (1987)

"G. K. Wertheim, S. Hüfner, Phys. Rev. Lett. 28, 1028 (1972).

${ }^{12}$ L. F. Mattheiss, Phys. Rev. Lett. 58, 1028 (1987).

${ }^{13}$ M. Romand, M. Roubin, and J. P. Deloume, J. Electron Spectr. 13, 229 (1978). 